\title{
A review of China's energy consumption structure and outlook based on a long-range energy alternatives modeling tool
}

\author{
Kang-Yin Dong ${ }^{1,2} \cdot$ Ren-Jin Sun ${ }^{1} \cdot$ Hui Li $^{1,3} \cdot$ Hong-Dian Jiang ${ }^{1}$
}

Received: 19 June 2016/Published online: 17 December 2016

(C) The Author(s) 2016. This article is published with open access at Springerlink.com

\begin{abstract}
China's energy consumption experienced rapid growth over the past three decades, raising great concerns for the future adjustment of China's energy consumption structure. This paper first presents the historical evidence on China's energy consumption by the fuel types and sectors. Then, by establishing a bottom-up accounting framework and using long-range energy alternatives planning energy modeling tool, the future of China's energy consumption structure under three scenarios is forecast. According to the estimates, China's total energy consumption will increase from 3014 million tonnes oil equivalent (Mtoe) in 2015 to 4470 Mtoe in 2040 under the current policies scenario, 4040 Mtoe in 2040 under the moderate policies scenario and 3320 Mtoe in 2040 under the strong policies scenario, respectively, lower than those of the IEA's estimations. In addition, the clean fuels (gas, nuclear and renewables) could be an effective alternative to the conventional fossil fuels (coal and oil) and offer much more potential. Furthermore, the industry sector has much strong reduction potentials than the other sectors. Finally, this paper suggests that the Chinese government should incorporate consideration of adjustment of the energy
\end{abstract}

Ren-Jin Sun

sunrenjin@cup.edu.cn

1 School of Business Administration, China University of Petroleum-Beijing, 102249 Beijing, China

2 Department of Agricultural, Food and Resource Economics, Rutgers, State University of New Jersey, New Brunswick, NJ 08901, USA

3 Energy Systems Research Center, University of Texas at Arlington, Arlington, TX 76019, USA

Edited by Xiu-Qin Zhu consumption structure into existing energy policies and measures in the future.

Keywords Energy consumption structure $\cdot$ China-LEAP model $\cdot$ Scenario analysis $\cdot$ Clean fuels $\cdot$ Industrial sector

\section{Introduction}

Energy is essential for economic and social development and the improvement of life in all the countries (Bilgen 2014). Energy consumption is a key lever to achieve more rapid development (Rennings et al. 2012). Most scholars claimed that there is a strong relationship between China's energy consumption and economic growth ( $\mathrm{Li}$ et al. 2014; Liao and Wei 2010; Zhang et al. 2011). China's energy consumption has increased dramatically since 2000 and is forecast to keep rising in the next several decades due to continuous economic growth. In the statistics of International Energy Agency (IEA), BP and the National Bureau of Statistics of China (NBS) (IEA 2015; BP 2016; NBS 2015), China's energy consumption increased from 131 million tonnes oil equivalent (Mtoe) (in 1965) to 3014 Mtoe (in 2015), with the GDP increasing from 172 billion yuan (in 1965) to 67,670 billion yuan (in 2015) (Fig. 1).

In China, the primary energy consumption includes five types, i.e., coal, oil, gas, nuclear and renewables, which are mainly used in the four sectors, i.e., transport, industry, building and others (Bilgen 2014). The China's 12th Five Year Plan set an ambitious goal, for which the adjustment of energy consumption structure should make significant progress during the 2011-2015 period. Thus, a number of studies have focused on China's energy consumption structure such as new energy development, energy 


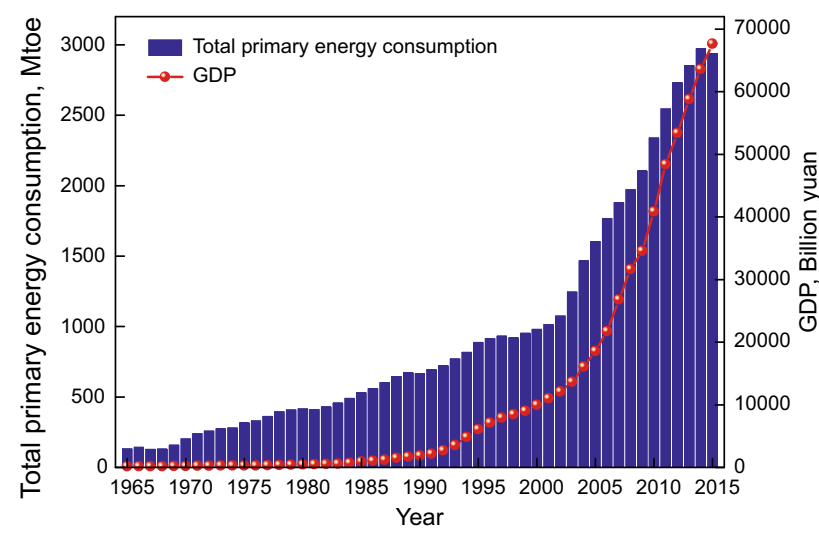

Fig. 1 Total energy consumption and GDP in China. Data source BP Statistical Review of World Energy (2016) and NBS China Statistical Yearbook (2015)

conservation and the improvement of energy efficiency (Lin and Wang 2015; Peng et al. 2015; Weidou and Johansson 2004). We need to consider China's energy consumption structure in the past, present and future. What energy plan should be worked out to guarantee the goal of the adjustment of energy consumption structure, as set by the State (China) for the 13th Five Year Plan, is achieved? These issues must be carefully solved before the energy strategies and policies are formulated. Hence, a review of China's energy consumption structure and outlook is valuable and may provide a guideline for policy-making.

The major aims of this paper are (1) to present a comprehensive and systematic investigation of China's energy consumption structure from the point of view of fuel types and sectors, (2) to analyze China's energy consumption structure in the future under three scenarios, by using the bottom-up accounting framework and LEAP (Stockholm Environment Institute, SEI 2014) energy modeling tool and (3) to describe the results and also propose policy suggestions.

\section{A review of China's energy consumption structure}

\subsection{China's energy consumption by fuel types}

\subsubsection{Coal}

Since the foundation of the People's Republic of China, China's energy has primarily come from coal (Govindaraju and Tang 2013). In comparison with oil and natural gas, coal is overwhelmingly abundant and more widely distributed in China. Therefore, coal is the principal energy source in China and it is given a strategic role in the economic growth of the country (Li and Leung 2012). Although the share of coal in the total energy consumption has fallen from $87.1 \%$ (in 1965) to $63.7 \%$ (in 2015)
(Fig. 2), coal has long been the dominant fuel type in China, soaring from 114 Mtoe (in 1965) to 1920 Mtoe (in 2015) (Fig. 3). Specifically, despite the increased economic growth and a continuous increase in China's coal consumption in 1965-1978, the share of coal in the total energy consumption gradually decreased from $87.1 \%$ to $71.3 \%$. After the introduction of the reform and opening-up policy, the consumption of coal in China has increased rapidly from 283 Mtoe (in 1978) to 664 Mtoe (in 1995). Following that, with the adjustment of energy consumption structure in 1995-2001 and the supply of coal being tightly limited in China, the share of coal in the total energy consumption has fallen gradually. However, China's actual coal consumption has increased dramatically since the turn of the millennium, considered as a result of rapid economic development, urbanization, energy shortages, etc. The consumption of coal increased from 679 Mtoe (in 2000) to 1920 Mtoe (in 2015), with an average annual growth rate of $7.2 \%$ (Fig. 3).

\subsubsection{Oil}

In China, oil is one of the important primary energy sources and has a strategic role in promoting economic growth. Since it initiated an economic reform program in 1978, China has witnessed rapid economic growth and an improved living standard (Zheng and Luo 2013). Meanwhile, oil consumption in China increased rapidly from 91 Mtoe (in 1978) to 560 Mtoe (in 2015) (Fig. 3), with an average annual growth of $5.0 \%$. However, China in not rich in oil resources, and its oil reserves account for only $2 \%$ of the world oil reserves. Hence, China is highly reliant on the oil imports, and about $61 \%$ of oil consumption was imported in 2015 (NBS 2015). Moreover, China became a net importer of crude oil in 1993, and the world's secondlargest oil consumer in 2002. Since the early 1990s, with

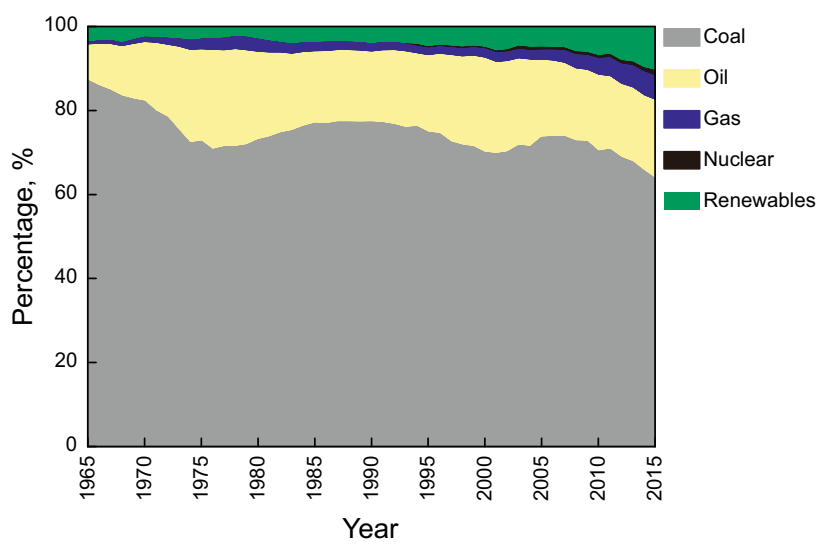

Fig. 2 Percentage of China's energy consumption structure by fuel types, 1965-2015. Data source BP Statistical Review of World Energy (2016) and NBS China Statistical Yearbook (2015) 


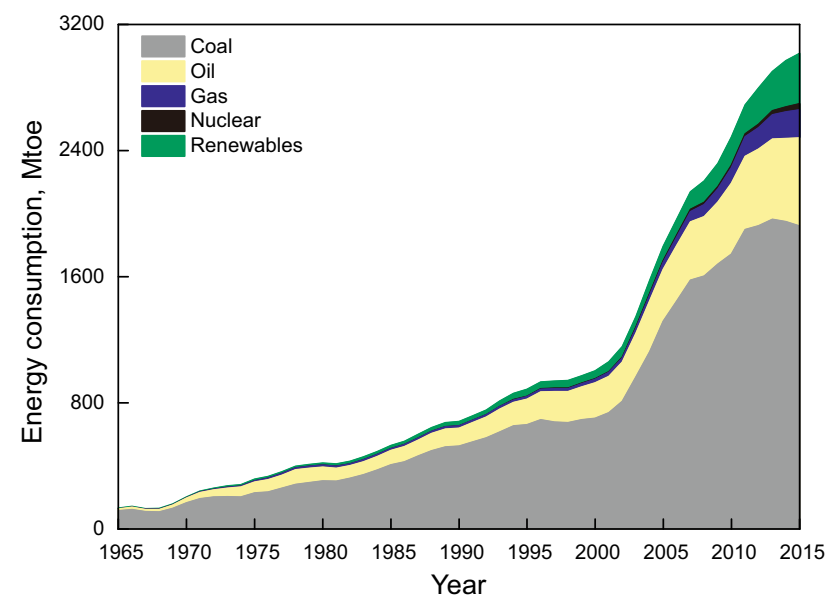

Fig. 3 History of China's energy consumption by different fuel types, 1965-2015. Data source BP Statistical Review of World Energy (2016) and NBS China Statistical Yearbook (2015)

increasing economic growth, improved quality of life and the booming development of automobile and aviation industry, total oil consumption in China has increased rapidly. The share of oil in total energy consumed has gradually increased, from $8.3 \%$ (in 1965) to $18.6 \%$ (in 2015) (Fig. 2).

\subsubsection{Gas}

Natural gas is an important energy source for power generation, chemical feedstock, residential usage, etc. (Mohr and Evans 2011). China possesses rich natural gas resources, and Chinese authorities have estimated that the TRR (technically recoverable resource) and URR (ultimately recoverable resources) of natural gas are 6.1 trillion cubic meters (tcm) and $37 \mathrm{tcm}$, respectively (Hou et al. 2015; Zou et al. 2015). Although China is rich in gas resources, the domestic natural gas industry in China developed slowly during its industrialized period. In 2015, natural gas consumption in China was 177.6 Mtoe, accounting for only $5.9 \%$ of the domestic energy needs (Fig. 2).

Recently, the government has begun to develop natural gas as a partial substitute for coal, due to the problems from high reliance on coal, such as air pollution, water contamination and greenhouse gas emissions. Natural gas consumption in China has soared since the dawn of the twenty-first century, from 24.7 Mtoe (in 2001) to 177.6 Mtoe (in 2015) (Fig. 3), with an average annual growth rate of $15.1 \%$.

\subsubsection{Nuclear}

Considering the rising cost of oil and natural gas and the enormous environmental pressure resulting from coal consumption, nuclear energy is an inevitable strategic option for China (Zhou and Zhang 2010). By the end of 2013, there were 17 nuclear power units in commercial operation in China (CNEA 2014; NRDC 2014), with production of 38.6 Mtoe (in 2015). Nuclear energy still only accounts for $1.3 \%$ of China's national energy needs (Fig. 2).

As one of the largest developing countries, the Chinese government began to develop nuclear energy in the 1980s. At the end of 1991, QNNP (Qinshan Nuclear Power Plant) was put into operation, and nuclear energy consumption in China increased slowly during the twentieth century. However, nuclear energy consumption in China has soared and continued to rise fast this century, from 4.0 Mtoe (in 2001) to 38.6 Mtoe (in 2015) (Fig. 3), with an average annual growth rate of $17.6 \%$.

\subsubsection{Renewables}

The first account of renewable electricity consumption in China dated back to the 1950s, and nationwide development of renewable electricity started at the end of the 1970s and especially after the reform and opening-up in 1978 (Fang 2011). Generally speaking, renewable electricity in China includes hydroelectric, wind, bioenergy, geothermal, solar and other renewables.

The development of renewable electricity in China can be divided into four stages since 1973 (Hao 2013), i.e., starting stage (1973-1992), the preliminary stage of industrialization (1993-2004), fast developing stage (2005-2009) and industrial-scale stage (2010-). Firstly, in the 1970s, Chinese government began to develop renewable electricity in response to energy shortages, which were caused by the World Energy Crisis. Since then, renewable electricity consumption in China increased gradually from 8.3 Mtoe (in 1973) to 29.6 Mtoe (in 1992), with an average annual growth rate of $6.6 \%$. Secondly, to accelerate the development of renewable electricity, some initiatives and laws were made by the government, e.g. China's Agenda 21 (enacted in 1992), Developing Program of New Energy and Renewable electricity during 1996-2010 (in 1995) as well as the Laws of Saving on Energy Resources in China (promulgated in 1998) (NBS 2015). In particular, China's Agenda 21 became effective on March 25, 1994, signaling China's new energy and renewable electricity industry stepped into the preliminary stage of industrialization. By the end of 2004, the renewable electricity consumption in China was 80.9 Mtoe, accounting for $5.5 \%$ of the national energy need. Thirdly, with the encouragement and support of the government, China's new energy and renewable electricity industry has made significant breakthroughs in technology during the period of 2005-2009. Furthermore, renewable electricity consumption in China increased 
rapidly from 90.9 Mtoe (in 2005) to 146.2 Mtoe (in 2009) (Fig. 3), with an average annual growth rate of $10.0 \%$. Lastly, in the industrial-scale stage, renewable electricity consumption in China has continued to rise fast, with the consumption of 319.5 Mtoe, accounting for $10.6 \%$ of the domestic energy needs by the end of 2015 (Fig. 2).

In summary, the adjustment of China's energy consumption structure is closely related to the stage of social development. The adjustment of China's energy consumption by fuel type for the study period of 1965-2015 can be summarized as follows: The share of coal in total energy consumed has gradually declined, the share of oil has gradually increased, the share of natural gas has rapidly increased, and the utilization of nuclear and renewables has rapidly increased. Hence, China's energy consumption structure has displayed a diversified trend, and the share of clean energy has gradually increased.

\subsection{China's energy consumption by sectors}

According to the data of IEA, China's energy consumption can be commonly divided into four energy-consuming enduse sectors, namely transport sector (TS), industry sector (IS), building sector (BS) and other sectors (OS). Notably, although the electricity sector (ES) is not included in the energy-consuming end-use sectors, it is essential to the industrialization and urbanization process, and indeed is an essential element to the transport, industry, building and other sectors of society (Dincer et al. 2012; Marton and Eddy 2012).

\subsubsection{Transport sector}

China is currently in the development stage of rapid urbanization (Lin and Du 2015), so the transportation sector accounts for a major share of energy consumption in China, with about $8.2 \%$ of the total energy consumption in 2013. Furthermore, in the period of 1990-2013, the energy demand of China's transportation sector increased gradually from 34 Mtoe (in 1990) to 249 Mtoe (in 2013), with its share in the total energy consumed rising from $4.0 \%$ (in 1990) to $8.2 \%$ (in 2013) (Fig. 4).

In addition, the most important component of energy used by the transportation sector is oil, and the oil demand of the transportation sector increased from $71 \%$ (in 1990) to $91 \%$ (in 2013). In contrast, the share of coal in total transportation energy consumed dramatically decreased from $29 \%$ (in 1990) to $1 \%$ (in 2013), simply because the change from coal powered (steam) locomotives to diesel and electric trains. Additionally, against the background of China's national energy conservation and emission reduction aims, especially in light of how to reach the emission reduction targets as put forward in the "12th Five Year

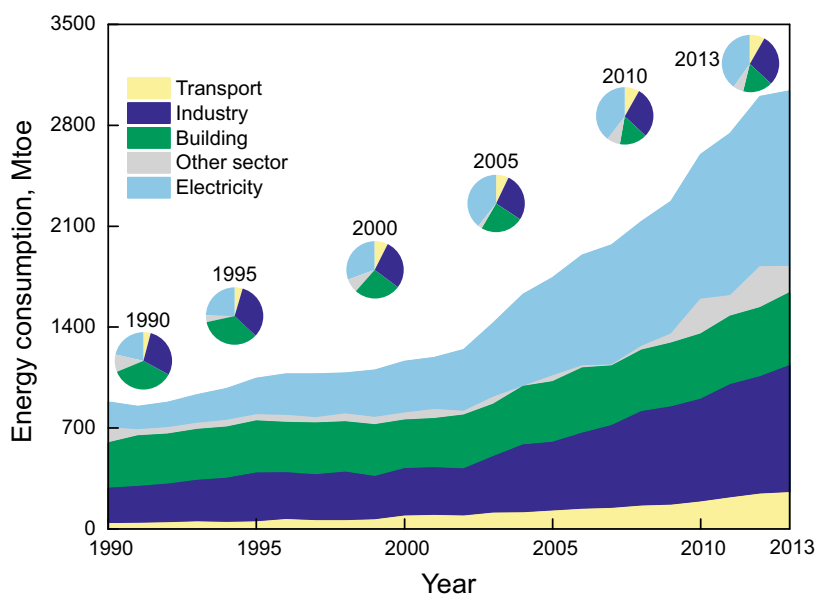

Fig. 4 Historical data of China's energy consumption by different sectors, 1990-2013. Data source BP Statistical Review of World Energy (2016), IEA World Energy Outlook (WEO) (2015) and NBS China Statistical Yearbook (2015)

Plan" (Lin and Du 2015), much more clean fuels (e.g. gas and renewables) are used in China's transportation sector. These three fuels (gas, electricity and renewables) accounted for $5 \%, 2 \%$ and $1 \%$ of transportation energy need, respectively, in 2013; however, these shares are still low (Table 1).

\subsubsection{Industry sector}

In the industrialization stage of China, economic growth is dominated by the industry sector (Ouyang and Lin 2015). The importance of China's industry sector is highlighted by its role in providing the massive employment opportunities and raw materials during the industrialization and urbanization process. With the rapid development of China's industry sector, energy consumption by the industry sector has increased rapidly over the past two decades, rising from 245 Mtoe (in 1990) to 881 Mtoe (in 2013), and the share in China total energy consumed rose from $27.9 \%$ (in 1990) to $29.0 \%$ (in 2013) (Fig. 4). Notably, a decrease in the industrial final energy use occurred during the period of 1995-2000, primarily because ownership restructuring in China's state industry was introduced (CEIC 2014).

Coal has dominated the energy consumption structure in China's industry sector for a long time (Ouyang and Lin 2015); however, the proportion of industrial final energy use decreased continuously from $74 \%$ (in 1990) to $54 \%$ (in 2013). In the meantime, the energy demand of China's industry sector for oil and gas is not massive, with the shares being $7 \%$ and $3 \%$ in 2013, respectively. In addition, the proportion of energy consumed in electrical power generation increased dramatically from $17 \%$ (in 1990) to $36 \%$ (in 2013) (Table 2). 
Table 1 Energy consumption by transport sector in China during 1990-2013. Data source IEA WEO (2015)

\begin{tabular}{|c|c|c|c|c|c|c|c|c|}
\hline & \multicolumn{6}{|c|}{ Energy consumption, Mtoe } & \multicolumn{2}{|c|}{ Shares, \% } \\
\hline & 1990 & 1995 & 2000 & 2005 & 2010 & 2013 & 1990 & 2013 \\
\hline Total & 34 & 46 & 88 & 135 & 208 & 249 & 100 & 100 \\
\hline Coal & 10 & 7 & 4 & 4 & 3 & 3 & 29 & 1 \\
\hline Oil & 24 & 39 & 83 & 128 & 193 & 226 & 71 & 91 \\
\hline Gas & 0 & 0 & 0 & 1 & 7 & 13 & 0 & 5 \\
\hline Electricity & 0 & 0 & 1 & 2 & 4 & 5 & 0 & 2 \\
\hline Renewables & 0 & 0 & 0 & 0 & 1 & 2 & 0 & 1 \\
\hline
\end{tabular}

Table 2 Energy consumption by industry sector in China during 1990-2013. Data source IEA WEO (2015)

\begin{tabular}{|c|c|c|c|c|c|c|c|c|}
\hline & \multicolumn{6}{|c|}{ Energy consumption, Mtoe } & \multicolumn{2}{|c|}{ Shares, $\%$} \\
\hline & 1990 & 1995 & 2000 & 2005 & 2010 & 2013 & 1990 & 2013 \\
\hline Total & 244 & 339 & 329 & 531 & 725 & 881 & 100 & 100 \\
\hline Coal & 180 & 249 & 215 & 331 & 403 & 475 & 74 & 54 \\
\hline Oil & 20 & 24 & 30 & 44 & 60 & 60 & 8 & 7 \\
\hline Gas & 3 & 4 & 5 & 10 & 17 & 33 & 1 & 4 \\
\hline Electricity & 41 & 62 & 78 & 146 & 245 & 313 & 17 & 36 \\
\hline
\end{tabular}

\subsubsection{Building sector}

As the second-largest energy consumer after the USA, China is also the second-largest building energy consumer worldwide (IEA 2015). Undoubtedly, energy consumption associated with China's building sector inevitably has displayed an upward trend along with the industrialization and urbanization process, and increased gradually from 314 Mtoe (in 1990) to 506 Mtoe (in 2013); however, its share in the total energy consumed dropped from $35.7 \%$ (in 1990) to $16.7 \%$ (in 2013) (Fig. 4). In the building sector, energy is used for equipment, providing heating, cooling, lighting and other household needs (Zhang et al. 2015). The energy types in BS have displayed a diversified trend. In the period of 1990-2013, the shares of oil, gas and electricity grew from $2 \%$ to $9 \%, 1 \%$ to $7 \%$ and $2 \%$ to $26 \%$, respectively. In contrast, the shares of coal and renewables decreased from $29 \%$ to $15 \%$ and $66 \%$ to $43 \%$, respectively (Table 3).

\subsubsection{Other sectors}

Losses occur when the efficiency of a device or process deviates from the efficiency that would occur if the device or process were ideal; and the low efficient heating system leads to enormous energy loss (Bilgen 2014). Generally, the energy consumption by the other sectors mainly refers to the energy losses in all the sectors (Dincer et al. 2012). Undoubtedly, with the energy consumption increasing, energy losses in all the sectors also increased rapidly over the past two decades, growing from 104 Mtoe (in 1990) to
184 Mtoe (in 2013), with the percentage in the total energy consumed of around $6.1 \%$ (Fig. 4).

Specifically, oil plays a key role in the energy losses in the sectors, and its share grew gradually from $41 \%$ (in 1990) to $50 \%$ (in 2013). In the meantime, the energy losses of electricity and renewables have inevitably displayed an upward trend, with their shares growing from $6 \%$ to $15 \%$ and $0 \%$ to $4 \%$, respectively. Notably, a decrease in the share of coal occurred during the period of 1990-2013, primarily because of the accelerating cleaning process of coal (Table 4).

\subsubsection{Electricity sector}

Due to the large population, the rapid economic development, as well as the process of urbanization and industrialization, China has a much higher demand for electricity than before (Shiu and Lam 2004; Yuan et al. 2007; Zhou et al. 2015). Energy consumption by China's power sector has soared and continued to rise fast since 1990, from 181 Mtoe (in 1990) to 1218 Mtoe (in 2013), with its share in domestic total energy consumed rising from $20.6 \%$ (in 1990) to $40.1 \%$ (in 2013) (Fig. 4).

Coal is overwhelmingly abundant and thermal power accounts for a large proportion in different power generation methods in China, so it has always been the main source of power generation. In 2013, it accounted for $86 \%$ of the power generation energy. Additionally, with the development of micro grids, smart grids and smart energyrelated concepts, techniques and systems, as well as the penetration of other energies, some unconventional power 
Table 3 Energy consumption by the building sector in China during 1990-2013. Data source IEA WEO (2015)

\begin{tabular}{|c|c|c|c|c|c|c|c|c|}
\hline & \multicolumn{6}{|c|}{ Energy consumption, Mtoe } & \multicolumn{2}{|c|}{ Shares, \% } \\
\hline & 1990 & 1995 & 2000 & 2005 & 2010 & 2013 & 1990 & 2013 \\
\hline Total & 303 & 315 & 305 & 353 & 400 & 506 & 100 & 100 \\
\hline Coal & 88 & 76 & 54 & 64 & 61 & 77 & 29 & 15 \\
\hline Oil & 7 & 17 & 19 & 28 & 35 & 43 & 2 & 9 \\
\hline Gas & 2 & 2 & 4 & 10 & 24 & 36 & 1 & 7 \\
\hline Electricity & 6 & 16 & 25 & 48 & 78 & 132 & 2 & 26 \\
\hline Renewables & 200 & 204 & 203 & 203 & 202 & 218 & 66 & 43 \\
\hline
\end{tabular}

Table 4 Energy consumption by the other sectors in China during 1990-2013. Data source IEA WEO (2015)

\begin{tabular}{|c|c|c|c|c|c|c|c|c|}
\hline & \multicolumn{6}{|c|}{ Energy consumption, Mtoe } & \multicolumn{2}{|c|}{ Shares, \% } \\
\hline & 1990 & 1995 & 2000 & 2005 & 2010 & 2013 & 1990 & 2013 \\
\hline Total & 83 & 91 & 94 & 145 & 195 & 184 & 100 & 100 \\
\hline Coal & 40 & 34 & 31 & 45 & 51 & 47 & 48 & 26 \\
\hline Oil & 34 & 45 & 48 & 71 & 94 & 93 & 41 & 50 \\
\hline Gas & 4 & 3 & 4 & 7 & 10 & 9 & 5 & 5 \\
\hline Electricity & 5 & 8 & 10 & 19 & 30 & 28 & 6 & 15 \\
\hline Renewables & 0 & 1 & 1 & 3 & 10 & 7 & 0 & 4 \\
\hline
\end{tabular}

Table 5 Energy consumption of power generation in China during 1990-2013. Data source IEA WEO (2015)

\begin{tabular}{|c|c|c|c|c|c|c|c|c|}
\hline & \multicolumn{6}{|c|}{ Energy consumption, Mtoe } & \multicolumn{2}{|c|}{ Shares, \% } \\
\hline & 1990 & 1995 & 2000 & 2005 & 2010 & 2013 & 1990 & 2013 \\
\hline Total & 181 & 275 & 360 & 682 & 1004 & 1218 & 100 & 100 \\
\hline Coal & 153 & 241 & 314 & 605 & 884 & 1047 & 85 & 86 \\
\hline Oil & 16 & 13 & 16 & 18 & 9 & 5 & 8 & 0 \\
\hline Gas & 1 & 1 & 5 & 7 & 20 & 27 & 1 & 2 \\
\hline Nuclear & 0 & 3 & 4 & 14 & 19 & 29 & 0 & 2 \\
\hline Renewables & 11 & 17 & 21 & 38 & 72 & 110 & 6 & 9 \\
\hline
\end{tabular}

generation methods have been implemented in China, such as the renewable electricity power (wind power, solar photovoltaic and hydroelectric power, etc.) (Chang et al. 2015; Yang and Shen 2013). Therefore, the share of renewables in total power generation energy consumed gradually increased from 6\% (1990) to 9\% (2013) (Table 5).

\section{Methodology}

\subsection{China-LEAP model framework}

In this methodology, the LEAP model is used as an energy accounting modeling tool to calculate China's energy consumption. LEAP was developed by the Stockholm Environmental Institute (SEI-US) (Schnaars 1987; Heaps 2002, 2012). Specifically, LEAP is a scenario-based energy environment modeling tool for energy policy analysis and can be used to track energy consumption, production and resource extraction in all the sectors (Chontanawat et al. 2014; Kemausuor et al. 2015). The aim of the model is to analyze the effects of multiple factors on energy consumption under different scenarios in an objective, quantitative and comprehensive way, to provide a reference for the policy makers and investors (Huang et al. 2011). As this paper is to study China's energy consumption structure by the fuel types and sectors, the LEAP model was chosen because (1) it allows users to build energy forecast systems based on existing energy demand and supply data, to prepare different long-run scenarios and to compare results with different scenarios (Ates 2015), (2) it has low initial data requirement and (3) it is free to use for developing country researchers and government agencies.

As Fig. 5 shows, a bottom-up accounting framework is established for China's-LEAP model to estimate China's energy consumption structure. From the perspective of the key drivers of energy use, seven key factors are considered 


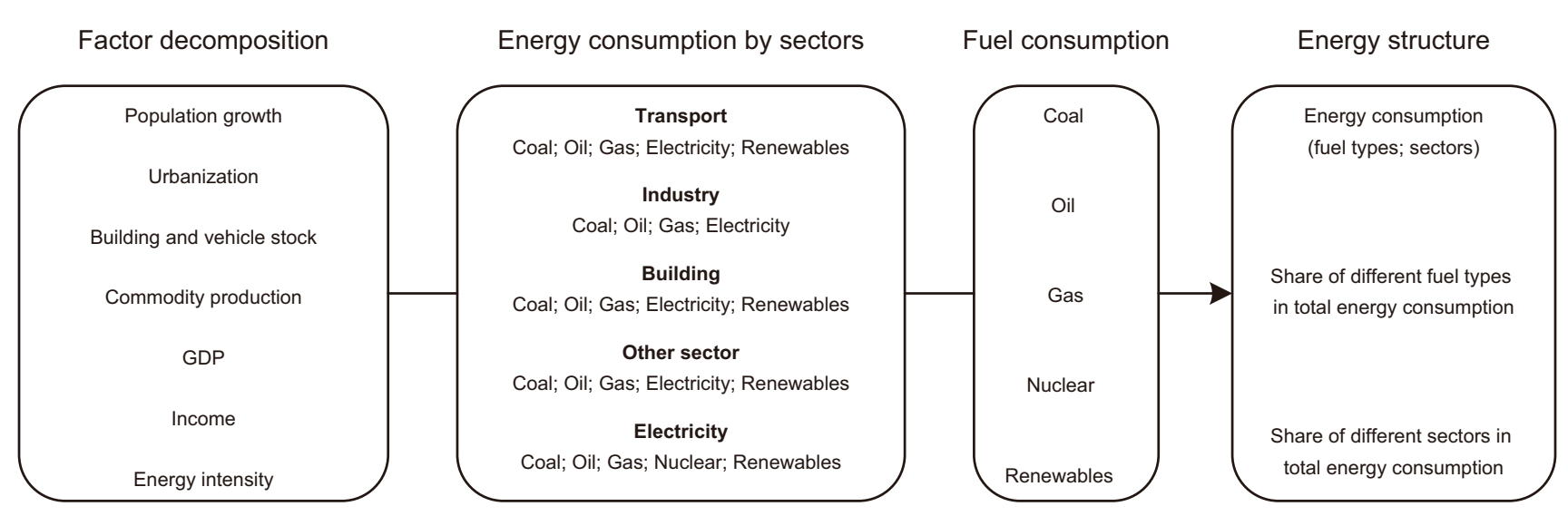

Fig. 5 Research framework for China-LEAP model

in the analysis, namely population growth, urbanization, building and vehicle stock, commodity production, GDP, income and energy intensity. In terms of the energy consumption sectors, they are mainly distributed in TS, IS, BS, OS and ES. Accordingly, fuel consumption considered in this study includes five types, namely coal, oil, gas, nuclear and renewables. Considering the accessibility and applicability of data information, Eqs. (1), (2) and (3) describe the calculation process employed in this study.

$$
\begin{aligned}
& \mathrm{EC}_{r}=\sum_{i} \mathrm{EC}_{i, j}=\sum_{j} \mathrm{EC}_{j, r} \\
& \mathrm{EC}_{i, j}=\sum_{j} \mathrm{EC}_{i, j, r} \\
& \alpha_{r}=\frac{\mathrm{EC}_{i, r}}{\mathrm{EC}_{R}} \mathrm{EC}_{i, j, r} \\
& \beta_{r}=\frac{\mathrm{EC}_{j, r}}{\mathrm{EC}_{r}}
\end{aligned}
$$

where, $\mathrm{EC}_{r}$ is the total primary energy consumption in year $r$ (Mtoe); $\mathrm{EC}_{i, r}$ is the total energy consumption of type $i$ fuel in year $r$ (Mtoe); $\mathrm{EC}_{j, r}$ is the total energy consumption of the sector $j$ in year $r$ (Mtoe); $\mathrm{EC}_{i, j, r}$ is the energy consumption of type $i$ fuel in the sector $j$ in year $r$ (Mtoe); $\alpha_{r}$ is the share of type $i$ fuel in the total energy consumption in year $r(\%) ; \beta_{r}$ is the share of the sector $j$ in the total energy consumption in year $r(\%)$.

The LEAP model consists of three blocks of programs, i.e., database, aggregation and scenarios (Shin et al. 2005). The LEAP model is based on exogenous input of the main parameters and factors (Perwez et al. 2015). In the LEAP model, the data set consists of various factors such as population growth, urbanization, GDP and energy intensity. To ensure the reliability of data, we have compiled data from (1) the available published literature, (2) the national official reports released by China's authorities such as NBS and (3) the international institutes' reports such as the WEO from IEA, the Statistical Review of World Energy from BP and the Annual Energy Outlook (AEO) from the US Energy Information Administration (EIA), while the real GDP data employed in our analysis are obtained from the NBS and the energy consumption data are from IEA, BP, EIA, etc. In addition, to ensure comparability after the data collection, data expressed in the various units are converted to the same unit in this paper; for example, energy consumption and GDP are expressed in Mtoe and billion yuan, respectively. Notably, in order to calculate the future energy consumption, the LEAP model uses the 2013 energy consumption as the baseline, and the energy consumption projection is done from 2015 to 2040 .

\subsection{Scenario examination}

\subsubsection{Current policies scenario (CPS)}

The CPS follows those policies and implemented measures which have been formally adopted; however, the policy adjustment effect on the CPS is limited. Since the CPS reflects what is expected to happen in terms of the policies and implemented measures, it is used as the reference scenario for evaluating China's energy consumption structure. Additionally, the assumptions of the key factors adopted for the CPS specified by the different sectors are shown in Table 6.

\subsubsection{Moderate policies scenario (MPS)}

The MPS assumes that policies and implemented measures have begun to affect China's energy markets, together with the successful improvement of energy efficiency. However, the relevant policies and specific measures need to be put into effect in this scenario. The assumptions of the key factors for the MPS specified by the different sectors are given in Table 7. 
Table 6 Key assumptions of the CPS for all the sectors

\begin{tabular}{ll}
\hline Sectors & Key assumptions \\
\hline TS & $\begin{array}{c}\text { Efficiency improvements in fuel economy are limited; Subsidies for hybrid and electric vehicles; Promotion of fuel-efficient cars; Cap } \\
\text { on passenger light-duty vehicles (PLDV) sales in some cities }\end{array}$ \\
IS & $\begin{array}{c}\text { Small plant closures and phasing out of outdated production capacity; Mandatory adoption of coke dry quenching and top-pressure } \\
\text { turbines }\end{array}$ \\
BS & $\begin{array}{l}\text { Application for construction conservation design standards } \\
\text { OS }\end{array}$ \\
Compared with 2013, the growth rate of energy losses will be below $20 \%$ in 2020 \\
ES & $40 \mathrm{GW}$ of new nuclear plants by 2050; Reaching $290 \mathrm{GW}$ of installed hydro-capacity, $100 \mathrm{GW}$ to wind, $35 \mathrm{GW}$ to solar by 2015 \\
\hline
\end{tabular}

Table 7 Key assumptions of the MPS for all the sectors

\begin{tabular}{|c|c|}
\hline Sectors & Key assumptions \\
\hline TS & Fuel economy target for PLDVs: $6.9 \mathrm{~L} / 100 \mathrm{~km}$ by $2015,5.0 \mathrm{~L} / 100 \mathrm{~km}$ by 2020 \\
\hline IS & $\begin{array}{l}\text { Contain the expansion of energy-intensive industries; Implementation of } \mathrm{CO}_{2} \text { pricing since } 2020 \text {; Reduction in industrial energy } \\
\text { intensity by } 21 \% \text { during } 2011-2015\end{array}$ \\
\hline BS & $\begin{array}{l}\text { Share of energy efficient building is } 30 \% \text { by } 2020 \text {; Implementation of energy price policy, such as reform heating price; Introduction of } \\
\text { energy standards; All fossil-fuel subsidies are phased out by } 2020\end{array}$ \\
\hline OS & Compared with 2013 , the growth rate of energy losses will be below $10 \%$ in 2020 \\
\hline ES & $\begin{array}{l}58 \mathrm{GW} \text { of nuclear capacity, } 200 \mathrm{GW} \text { of wind, } 100 \mathrm{GW} \text { of solar PV and } 30 \mathrm{GW} \text { of bioenergy by } 2020 \text {; Implementation of } \mathrm{CO}_{2} \text { pricing } \\
\text { after } 2020\end{array}$ \\
\hline
\end{tabular}

Table 8 Key assumptions of the SPS for all the sectors

\begin{tabular}{ll}
\hline Sectors & Key assumptions \\
\hline TS & Compared with 2010, 55\% efficiency improvements by 2040 and support for the use of biofuels; Enhanced support to alternative fuels \\
IS & Introducing the $\mathrm{CO}_{2}$ pricing by 2020; Enhanced energy efficiency standards; Support the introduction of CCS \\
BS & $95 \%$ of new building achieve saving of $55 \%-65 \%$ in space heating compared to 1980 \\
OS & Compared with 2013, the growth rate of energy losses will be below 5\% in 2020 \\
ES & Higher $\mathrm{CO}_{2}$ pricing; Enhanced support for renewables; Continued support to nuclear capacity additions post-2020; Deployment of CCS \\
& $\quad$ rom around 2020 \\
\hline
\end{tabular}

\subsubsection{Strong policies scenario (SPS)}

Compared with the other scenarios, the SPS sets out a much more aggressive energy pathway, which is consistent with stronger energy efficiency policies. Furthermore, this scenario assumes more vigorous policy actions are to be implemented after 2020. The assumptions of the key factors for the SPS specified by the different sectors are shown in Table 8.

\section{Results and discussion}

\subsection{Results}

Based on the three scenarios introduced in Sect. 3.2, the future energy consumption structure of China is established, as presented in the energy consumption by the sectors, energy consumption by the fuel types and total energy consumption.

\subsubsection{Energy consumption by sectors}

The results of China's energy consumption by different sectors under the three scenarios are shown in Figs. 6, 7 and 8, respectively. Figure 6 presents the energy consumption of different sectors under the CPS in 2010-2040. The energy consumption of the different sectors (TS, IS, BS, OS and ES) under the CPS will maintain the rising trend, reaching 600, 1253, 625, 393 and 2606 Mtoe, respectively, in 2040. However, as shown in Table 9, the growth rates of energy consumption by the different sectors under CPS will drop during the 2000-2040 period. For example, the growth of energy consumption by the TS under the CPS will be $10.0 \%, 6.2 \%, 4.6 \%$ and $1.3 \%$ during the ten-year periods from 2000 to 2040. 


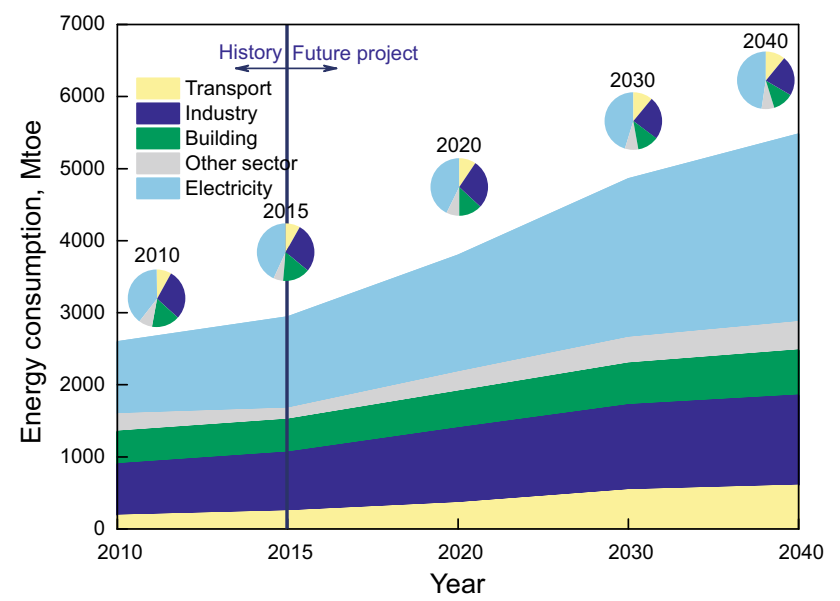

Fig. 6 Energy consumption of different sectors under the CPS in 2010-2040

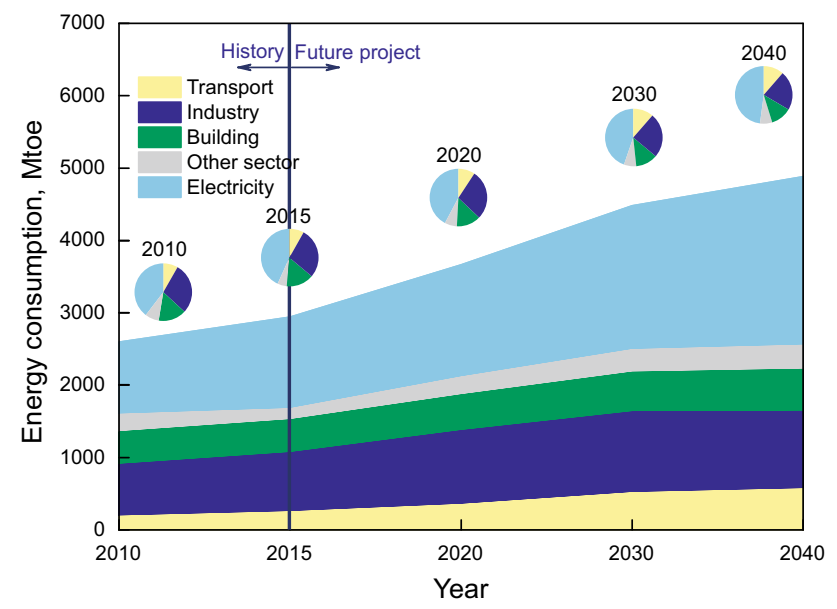

Fig. 7 Energy consumption of different sectors under the MPS in 2010-2040

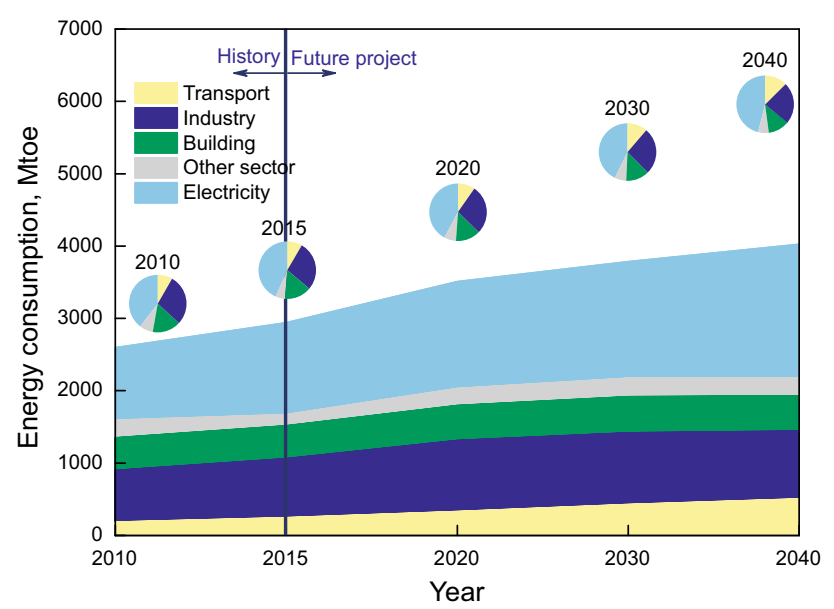

Fig. 8 Energy consumption of different sectors under the SPS in 2010-2040
As shown in Fig. 6, IS takes the dominating share of the total primary energy consumption under the CPS all the way through 2040, although the share will decrease from $27.5 \%$ in 2010 to $22.9 \%$ in 2040 . Meanwhile, BS and OS have inevitably displayed a downward trend, with their shares decreasing from $17.4 \%$ (in 2010) to $11.4 \%$ (in 2040) and $9.3 \%$ (in 2010) to $7.2 \%$ (in 2040), respectively. Notably, although the energy consumption of the TS is not high, its share will increase from $7.1 \%$ in 2010 to $11.0 \%$ in 2040.

Figure 7 presents the energy consumption of different sectors under the MPS in 2010-2040. Compared with the CPS, energy consumption in the different sectors (TS, IS, BS, OS and ES) under the MPS will decrease, reaching 559, 1072, 580, 333 and 2337 Mtoe, respectively, in 2040. Moreover, as shown in Table 9, the growth of energy consumption under MPS will be lower than that under CPS. Notably, the growth of the energy consumption in the IS under the MPS will be $-0.4 \%$ during the 2030-2040 period. The main reason is that policies and implemented measures under the MPS will have begun to affect China's energy markets, together with the successful improvement of energy efficiency.

In terms of the shares of the total primary energy consumption by different sectors under the MPS, IS still comprises the dominant share of the total primary energy consumption, maintaining its level at roughly $43.6 \%$ of the total primary energy consumption in 2040. BS is the second-largest energy-consuming end-use sector, with its share maintaining at around $22.8 \%$ of the total primary energy consumption in 2040. The share of the total primary energy consumption by the TS will increase from $14.0 \%$ in 2012 to $22.0 \%$ in 2040. Although the share of the total primary energy consumption by the OS under the MPS will keep rising, it will account for about $13.1 \%$ of the total primary energy consumption in 2040 , lower than that under the CPS.

Figure 8 presents the energy consumption of different sectors under the SPS in 2010-2040. Compared with the other scenarios, the policies and implemented measures under the SPS will be more aggressive and effective. Energy consumption by the different sectors (TS, IS, BS, OS and ES) under the SPS will be lower than that of the other two scenarios, reaching 5.3, 937, 490, 243 and 1850 Mtoe, respectively, in 2040. Furthermore, as shown in Table 9, the growth rates of energy consumption under the SPS will also be lower than that under the CPS and MPS. Specifically, the growth rates of energy consumption in the IS, BS and OS under the SPS will be negative during the 2030-2040 period.

Additionally, as shown in Fig. 8, compared with the MPS, the shares of the total primary energy consumption by the IS and BS under the SPS will change slightly, 
Table 9 Growth rates of energy consumption in the different sectors under the three scenarios in 2000-2040 (\%)

\begin{tabular}{|c|c|c|c|c|c|c|c|c|c|c|c|c|}
\hline & \multicolumn{4}{|l|}{ CPS } & \multicolumn{4}{|l|}{ MPS } & \multicolumn{4}{|l|}{ SPS } \\
\hline & $2000-10$ & 2010-20 & $2020-30$ & $2030-40$ & $2000-10$ & 2010-20 & $2020-30$ & $2030-40$ & $2000-10$ & 2010-20 & $2020-30$ & $2030-40$ \\
\hline TS & 10.0 & 6.2 & 4.6 & 1.3 & 10.0 & 5.8 & 4.4 & 1 & 10.0 & 5.2 & 2.9 & 1.9 \\
\hline IS & 9.2 & 4.1 & 1.4 & 0.7 & 9.2 & 3.9 & 1.0 & -0.4 & 9.2 & 3.4 & 0.1 & -0.6 \\
\hline BS & 3.1 & 2.6 & 1.5 & 0.9 & 3.1 & 2.4 & 1.2 & 0.6 & 3.1 & 2.1 & 0.4 & -0.2 \\
\hline OS & 8.4 & 3.6 & 3.2 & 1.1 & 8.4 & 2.7 & 2.6 & 0.8 & 8.4 & 2.1 & 0.9 & -0.5 \\
\hline ES & 12.1 & 5.5 & 3.5 & 1.9 & 12.1 & 5.0 & 2.8 & 1.8 & 12.1 & 4.4 & 1.0 & 1.5 \\
\hline
\end{tabular}

reaching $43.1 \%$ and $22.5 \%$ in 2040. Meanwhile, with more effective measures implemented, the share of the total primary energy consumption by the TS under the SPS will increase dramatically from $14.0 \%$ in 2012 to $22.0 \%$ in 2040. Moreover, the share of the total primary energy consumption by the OS under the MPS will decrease significantly, lower than that under the other scenarios, accounting for about $11.2 \%$ of the total primary energy consumption in 2040.

\subsubsection{Energy consumption by fuel types}

China's energy consumption by fuel type under the three scenarios is shown in Figs. 9, 10 and 11. Figure 9 shows the energy consumption of different fuel types (coal, oil, gas, nuclear and renewables) under the CPS in 2010-2040. The forecast result in Fig. 9 indicates that the energy consumption of the different fuel types under the CPS will keep rising, reaching 2362, 785, 487, 284 and 549 Mtoe, respectively, in 2040. Generally, the growth rates of the energy consumption by the different fuel types under the CPS will be decreasing during the every ten-year period from 2000 to 2040 (Table 10). Specifically, the growth rate of the coal consumption under the CPS will decrease dramatically during the same period, namely $10.1 \%, 1.8 \%$, $1.7 \%$ and $0.8 \%$.

Figure 9 also shows that coal makes up the dominant share of the total energy consumption under the CPS all the way to 2040 , although the share will decrease from $68.8 \%$ in 2010 to $52.9 \%$ in 2040 . The share of oil consumed in the total energy consumption will hover around $17.8 \%$. Meanwhile, the shares of the total consumption of gas, nuclear and renewables under CPS will keep rising, reaching $10.9 \%, 6.4 \%$ and $12.3 \%$, respectively, in 2040 .

Figure 10 shows the energy consumption of different fuel types under the MPS in 2010-2040. Compared with the CPS, energy consumption in the terms of coal and oil under the MPS will be lower, reaching 1867 and 687 Mtoe, respectively, in 2040. Meanwhile, as shown in Table 10, the growth rates of the coal and oil consumption under the MPS will be lower than that of the CPS. Furthermore, the consumption of gas, nuclear and renewables under the

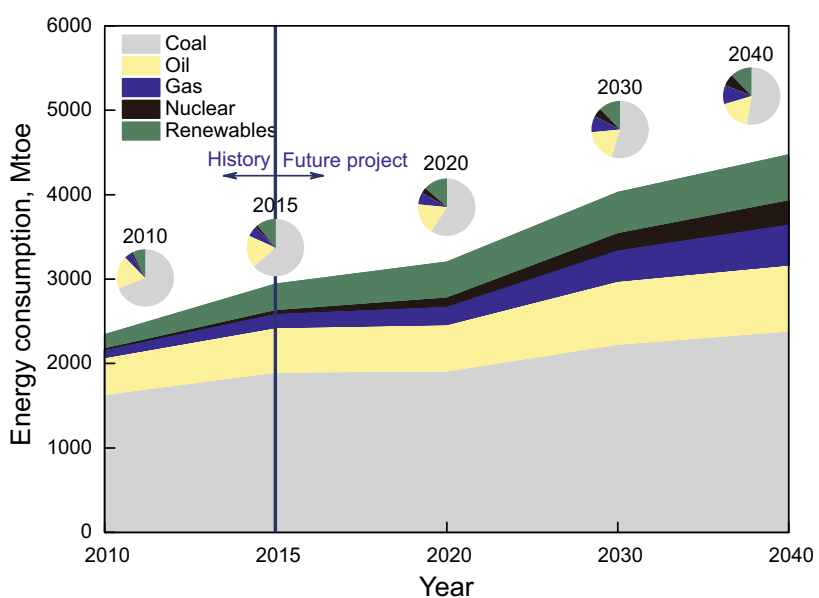

Fig. 9 Energy consumption of different fuel types under the CPS in 2010-2040

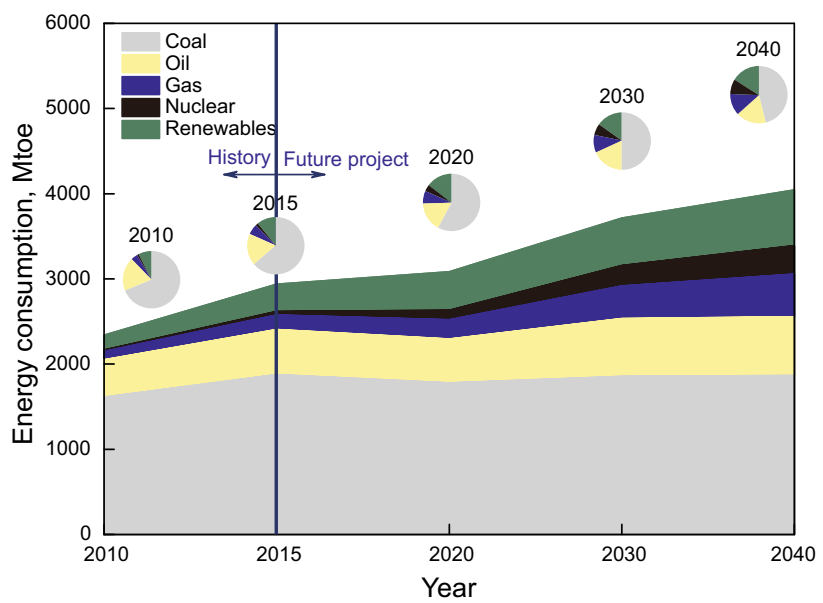

Fig. 10 Energy consumption of different fuel types under the MPS in 2010-2040

MPS will be higher than that of the CPS, reaching 502, 335 and 654 Mtoe, respectively, in 2040 (Fig. 10). In addition, the growth rate of the gas, nuclear and renewables consumption under the MPS will also be higher than that of the CPS, reaching $3.1 \%, 4.0 \%$ and $1.8 \%$, respectively, in 2040, offering more potential than the conventional fossil fuels (coal and oil). 


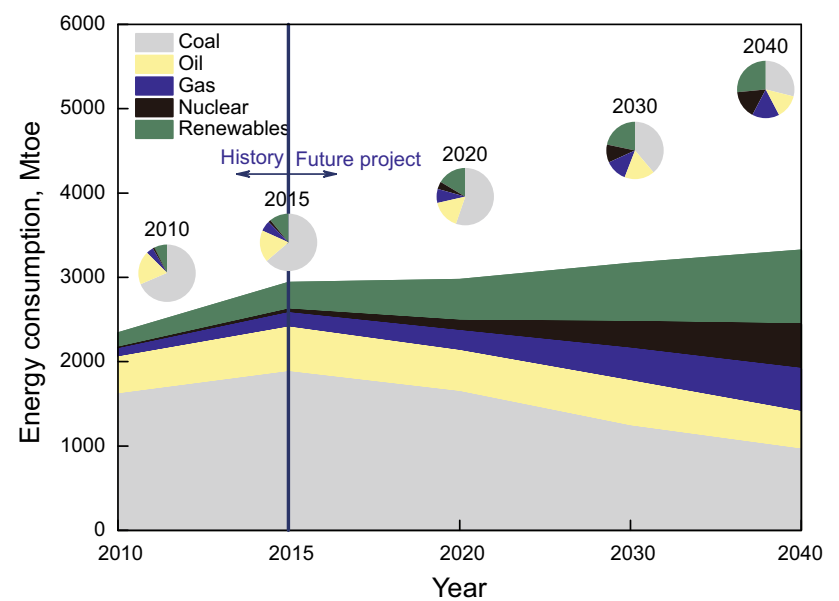

Fig. 11 Energy consumption of different fuel types under the SPS in 2010-2040

Figure 10 also shows that although coal and oil account for $87.6 \%$ and $63.1 \%$ of the total energy consumption in 2010 and 2040, respectively, their shares under the MPS will keep a decreasing trend. In contrast, gas, nuclear and renewables would be a major alternative to coal and oil, with their shares increasing to $12.4 \%, 8.3 \%$ and $16.2 \%$, respectively, in 2040.

Figure 11 shows the energy consumption of different fuel types under the SPS in 2010-2040. Unlike the other two scenarios, Fig. 11 shows a downward trend both in the coal and in oil consumption under the SPS over the period from 2015 to 2040, reaching 958 and 445 Mtoe, respectively, in 2040. Furthermore, the growth rates of the coal and oil consumption under the SPS will be lower than that of the CPS and MPS. The growth rate of coal consumption under the SPS will be $10.1 \%$, $0.2 \%,-3.1 \%$ and $-2.7 \%$ during the ten-year periods from 2000 to 2040 (Table 10). Figure 11 shows an upward trend in the gas, nuclear and renewables consumption under the SPS over the period from 2015 to 2040 , reaching 510, 529 and 879 Mtoe, respectively, in 2040. Table 10 shows that the growth rate of this section of energy consumption under the SPS will be lower than that of the other scenarios.

Figure 11 also shows that coal and oil no longer comprise the dominant share of the total energy consumption under the SPS in 2040, with their total shares standing at $45.0 \%$. Moreover, with more aggressive energy efficiency policies and more vigorous policy action to be implemented, clean fuels (gas, nuclear and renewables) will keep an increasing trend, with their shares rising to $13.4 \%$, $15.4 \%$ and $26.5 \%$, respectively, in 2040.

\subsubsection{Total energy consumption}

Figure 12 presents the total energy consumption in China under the different scenarios in 2010-2040. It can be seen

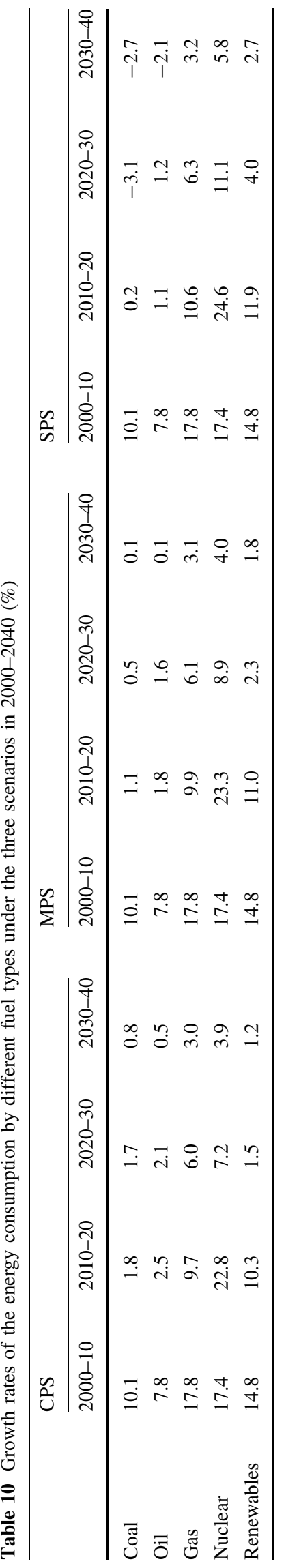




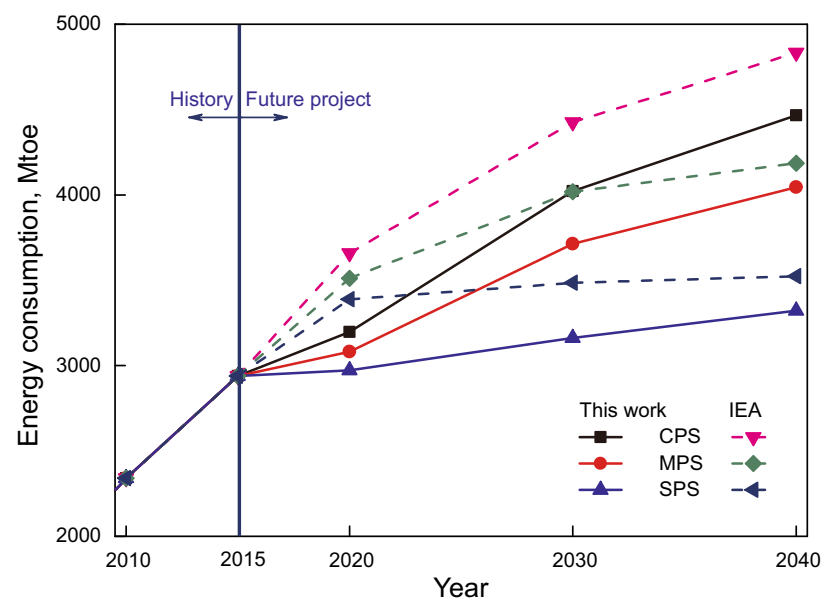

Fig. 12 Total energy consumption under different scenarios in 2010-2040

that by 2040, the total energy consumption in China will still be increasing under most of the scenarios. Total energy consumption will increase from 3016 Mtoe in 2015 to 4467 Mtoe in 2040 under the CPS. Compared with the CPS, it will decrease by 422 Mtoe to 4045 Mtoe in 2040 under the MPS, while it will decrease by 1146 Mtoe to 3321 Mtoe in 2040 under the SPS. The average annual growth rates of the total energy consumption in China under the different scenarios (CPS, MPS and SPS) will be $1.6 \%, 1.2 \%$ and $0.4 \%$, respectively, over the period from 2015 to 2040. However, our estimates in this work are all lower than the IEA's ones.

\subsection{Discussion}

Prediction results of China's energy consumption by the transport sector (TS) in the present study and previous studies are shown in Table 11 for comparison purposes. As Table 11 shows, Ou et al. (2010) estimated Chinese TS energy consumption in 2020, 2030 and 2040 to be 375, 479 and 531 Mtoe, respectively, under the business as usual (BAU) scenario; and to be 350, 427 and 426 Mtoe, respectively, under the promoting electric vehicles (PEV) scenario. Compared with the values reported by Ou et al.

Table 11 Chinese TS energy consumption estimated in the previous studies (Mtoe) (Ou et al. 2010; IEA 2015) and in this work

\begin{tabular}{|c|c|c|c|c|c|c|c|c|}
\hline & \multicolumn{2}{|c|}{ Ou et al. $(2010)^{\mathrm{a}}$} & \multicolumn{3}{|c|}{ IEA (2015) } & \multicolumn{3}{|c|}{ This study } \\
\hline & BAU & PEV & CPS & NPS & 450 & CPS & MPS & SPS \\
\hline 2020 & 375 & 350 & 348 & 346 & 336 & 357 & 345 & 329 \\
\hline 2030 & 479 & 427 & 482 & 465 & 414 & 535 & 509 & 425 \\
\hline 2040 & 531 & 426 & 564 & 520 & 428 & 600 & 559 & 503 \\
\hline
\end{tabular}

${ }^{a}$ The figures in BAU and PEV are estimated through the results calculated by $\mathrm{Ou}$ et al. (2010)
(2010), our results in this work are initially conservative for the first decade under the scenario and then become more optimistic. In addition, even though the trends of the IEA's predictions for the various scenarios were in line with those of our predictions; however, our predicted values were lower than those of the IEA for all three scenarios. The discrepancies between the IEA's predictions and ours could be attributed to the following three reasons. Firstly, the IEA's predictions are weighted heavily toward the 12th Five year Plan set in 2011, which underestimated the rigorous measures undertaken by the Chinese government for improving energy efficiency and reducing environmental impacts achieved in 2015. Secondly, China is not one of the IEA's 28-member countries. Hence, the IEA's data sources were likely obtained through third parties and might not reflect China's current situation. Thirdly, there are different assumptions used in this work and the IEA's calculations for the three scenarios.

Regarding the reduction potential of the energy consumption, there will be a maximum reduction of 1146 Mtoe of energy consumption under the SPS in 2040 compared with the CPS, and the SPS has much more reduction potentials. However, compared with much more aggressive energy efficiency policies under the SPS, the ongoing energy policies and measures in China show lower availabilities, efficiency and potentials. In this regard, some much more effective and advisable policies and measures should be put forward by the Chinese government.

When the results shown in Figs. 6, 7, 8, 9, 10, 11 and 12 are studied together, it can be concluded that the clean fuels (gas, nuclear and renewables) could be major alternatives to the conventional fossil fuels (coal and oil) and offer much more potential, accounting for $57.8 \%$ of the total energy consumption in 2040 under SPS, reaching 1918 Mtoe. In terms of the energy consumption by the sectors, IS has much more reduction potential than the other sectors. Compared with the CPS, the energy consumption will be reduced by 316-937 Mtoe in 2040 under the SPS. Hence, policy makers should pay attention to the development of Chinese clean fuels and to the energy reduction in the IS.

\section{Conclusions and policy implications}

\subsection{Policy implications}

From the comprehensive analysis and discussion carried out above, we obtain the following policy implications:

First, it will be necessary to incorporate consideration of the adjustment of energy consumption structure into the industrialization and urbanization process. Currently, compared with energy consumption, the government gives 
high priority to energy production and ignores the importance of adjustment of energy consumption structure. Hence, it is essential that in future the government should consider energy consumption structure from a strategic height and long-term perspective, adjusting the energy development strategy according to the adjustment of energy consumption structure.

Second, it is critical to establish and perfect the related policies and measures. This is the most important measure, chiefly because the China's energy market has experienced a lack of more aggressive energy efficiency policies and more vigorous policy actions for decades. For example, the resource tax in China's energy market has been comprehensively introduced. However, the stringency level of the resource tax has generally lagged behind that of developed countries. Furthermore, it is difficult to implement some energy market policies and measures in China.

Third, more focus should be laid on the development of clean fuels and energy reduction in the IS. In order to promote the development of clean fuels, the policy makers should improve existing pricing and subsidy policies. Besides, according to the adjustment of the energy consumption structure, the government should reasonably adjust the shares between the clean fuels and conventional fossil fuels. Furthermore, the government and enterprises should pay attention to the structural energy saving especially of the IS.

\subsection{Conclusions}

In this study, to forecast China's energy consumption structure in the future, we first present a comprehensive and systematic review of the development status of China's energy consumption structure by the fuel types from 1990 to 2015 and the sectors from 1990 to 2013. Then, under the CPS, MPS and SPS, a bottom-up accounting framework was developed and the LEAP model was used to forecast the China's energy consumption structure from 2015 to 2040. At last, the suggestions in the four aspects are proposed to further promote the adjustment of the China's energy consumption structure. The main conclusions drawn from this study are summarized as follows:

(1) From the perspective of energy consumption by the sectors, IS takes the dominant share of the total primary energy consumption under the three scenarios all the way to 2040 and the share will display an upward trend. In addition, compared with other energy-consuming end-use sectors, IS will offer more energy reduction potential. The energy consumption of the IS in 2040 under the SPS will be lower by 316 Mtoe than that under the CPS.
(2) From the perspective of energy consumption by the fuel types, coal and oil take the dominant share of the total energy consumption under the three scenarios all the way to 2040; however, the share will maintain a decreasing trend. In contrast, clean fuels will reach 1918 Mtoe, accounting for $57.8 \%$ of the total energy consumption in 2040 under the SPS. Therefore, the clean fuels will offer more development potential than conventional fossil fuels in the future.

(3) From the perspective of the total energy consumption, China's total energy consumption will increase continuously in all scenarios from 2015 to 2040. Specifically, the total energy consumption will increase from 3016 Mtoe in 2015 to 4467 Mtoe in 2040 under the CPS, 4045 Mtoe in 2040 under the CPS and 3321 Mtoe in 2040 under the CPS, respectively. It is notable that our estimates are all lower than the IEA's.

(4) From the perspective of the existing policies and measures, by analyzing the results under the three scenarios, we can find that the effect of the policies and measures under the CPS is poorer than those under the MPS and SPS, which means that existing policies and measures show lower availabilities, efficiency and potentials.

In summary, compared with that of the developed countries, China's energy consumption structure still needs the further improvement and adjustment. As a result, the Chinese government should incorporate consideration of the adjustment of energy consumption structure into existing energy policies and measures.

Acknowledgements This study is supported by National Natural Science Foundation (No. 71273277) and National Social Science Foundation (No. 13\&ZD159). The authors appreciate the helpful reviews and comments by the anonymous reviewers.

Open Access This article is distributed under the terms of the Creative Commons Attribution 4.0 International License (http://creative commons.org/licenses/by/4.0/), which permits unrestricted use, distribution, and reproduction in any medium, provided you give appropriate credit to the original author(s) and the source, provide a link to the Creative Commons license, and indicate if changes were made.

\section{References}

Ates SA. Energy efficiency and $\mathrm{CO}_{2}$ mitigation potential of the Turkish iron and steel industry using the LEAP (long-range energy alternatives planning) system. Energy. 2015;90:417-28. doi:10.1016/j.energy.2015.07.059.

Bilgen S. Structure and environmental impact of global energy consumption. Renew Sustain Energy Rev. 2014;38:890-902. doi:10.1016/j.rser.2014.07.004. 
BP Statistical Review of World Energy 2016. http://www.bp.com/en/ global/corporate/energy-economics/statistical-review-of-worldenergy.html. Accessed 20 Jun 2016.

CEIC. China economic and industry data database, 2014. http://www. ceicdata.com/en/countries/china (in Chinese).

Chang K, Xue F, Yang W. Review of the basic characteristics and technical progress of smart grids in China. Autom Electric Power Syst. 2015;33:10-5. doi:10.3321/j.issn:1000-1026.2009.17.003 (in Chinese).

Chontanawat J, Wiboonchutikula P, Buddhivanich A. Decomposition analysis of the change of energy intensity of manufacturing industries in Thailand. Energy. 2014;77:171-82. doi:10.1016/j. energy.2014.05.111.

CNEA. National nuclear security and operation in 2013. 2014. http:// www.china-nea.cn/html/2014-02/28741.html. Accessed $11 \mathrm{Feb}$ 2014 (in Chinese).

Dincer I, Rosen MA. Exergy: energy, environment and sustainable development. Newnes: Elsevier; 2012.

Fang Y. Economic welfare impacts from renewable energy consumption: the China experience. Renew Sustain Energy Rev. 2011;15:5120-8. doi:10.1016/j.rser.2011.07.044.

Govindaraju VC, Tang $\mathrm{CF}$. The dynamic links between $\mathrm{CO}_{2}$ emissions, economic growth and coal consumption in China and India. Appl Energy. 2013;104:310-8. doi:10.1016/j.ape nergy.2012.10.042.

Hao XD. A study of the Sino-US energy consumption structures. Wuhan: Wuhan University; 2013 (in Chinese).

Heaps C. Long-range energy alternatives planning (Leap) system. [Software Version 2011.0043]. Somerville: Stockholm Environment Institute; 2012.

Heaps C. Integrated energy-environment modelling and LEAP. SEI, 2002. http://www.energycommunity.org/default.asp.

Hou Z, Xie H, Zhou H, et al. Unconventional gas resources in China. Environ Earth Sci. 2015;73:5785-9. doi:10.1007/s12665-0154393-8.

Huang Y, Bor YJ, Peng CY. The long-term forecast of Taiwan's energy supply and demand: LEAP model application. Energy Policy. 2011;39:6790-803. doi:10.1016/j.enpol.2010.10.023.

IEA. World Energy Outlook 2015. http://www.worldenergyoutlook. org/ (2015). Accessed 20 Jan 2016.

Kemausuor F, Nygaard I, Mackenzie G. Prospects for bioenergy use in Ghana using long-range energy alternatives planning model. Energy. 2015;93:672-82. doi:10.1016/j.energy.2015.08.104.

Liao H, Wei YM. China's energy consumption: a perspective from Divisia aggregation approach. Energy. 2010;35:28-34. doi:10. 1016/j.energy.2009.08.023.

Li F, Song Z, Liu W. China's energy consumption under the global economic crisis: decomposition and sectoral analysis. Energy Policy. 2014;64:193-202. doi:10.1016/j.enpol.2013.09.014.

Lin B, Wang A. Estimating energy conservation potential in China's commercial sector. Energy. 2015;82:147-56. doi:10.1016/j. energy.2015.01.021.

Li R, Leung GC. Coal consumption and economic growth in China. Energy Policy. 2012;40:438-43. doi:10.1016/j.enpol.2011.10. 034.

Lin B, Du Z. How China's urbanization impacts transport energy consumption in the face of income disparity. Renew Sustain Energy Rev. 2015;52:1693-701. doi:10.1016/j.rser.2015.08.006.

Marton K, Eddy WF. Effective tracking of building energy use: improving the commercial buildings and residential energy consumption surveys. Washington: National Academies Press; 2012.

Mohr S, Evans G. Long term forecasting of natural gas production. Energy Policy. 2011;39:5550-60. doi:10.1016/j.enpol.2011.04. 066.
NBS. China statistical yearbook 2015. http://www.stats.gov.cn/tjsj/ ndsj/2015/indexeh.htm.

NRDC. Effective regulation of nuclear energy development, avoid repeating the mistakes of Fukushima, 2014. (in Chinese).

Ouyang X, Lin B. An analysis of the driving forces of energy-related carbon dioxide emissions in China's industrial sector. Renew Sustain Energy Rev. 2015;45:838-49. doi:10.1016/j.rser.2015. 02.030 .

Ou XM, Zhang XL, Chang SY. Scenario analysis on alternative fuel/ vehicle for China's future road transport: life-cycle energy demand and GHG emissions. Energy Policy. 2010;38:3943-56. doi:10.1016/j.enpol.2010.03.018.

Peng L, Zeng X, Wang Y, et al. Analysis of energy efficiency and carbon dioxide reduction in the Chinese pulp and paper industry. Energy Policy. 2015;80:65-75. doi:10.1016/j.enpol.2015.01.028.

Perwez U, Sohail A, Hassan SF, et al. The long-term forecast of Pakistan's electricity supply and demand: an application of long range energy alternatives planning. Energy. 2015;93:2423-35. doi:10.1016/j.energy.2015.10.103.

Rennings K, Brohmann B, Nentwich J, et al. Sustainable energy consumption in residential buildings. New York: Springer; 2012.

Schnaars SP. How to develop and use scenarios. Long Range Plan. 1987;20:105-14. doi:10.1016/0024-6301(87)90038-0.

Shin HC, Park JW, Kim HS, et al. Environmental and economic assessment of landfill gas electricity generation in Korea using LEAP model. Energy Policy. 2005;33:1261-70. doi:10.1016/j. enpol.2003.12.002.

Shiu A, Lam PL. Electricity consumption and economic growth in China. Energy Policy. 2004;32:47-54. doi:10.1016/s03014215(02)00250-1.

Stockholm Environment Institute (SEI). Long range energy alternatives planning system 2014. Joint IEA-IEF-OPEC report. http:// www.opec.org/opec_web/en/publications. Accessed 20 Oct 2015.

Weidou N, Johansson TB. Energy for sustainable development in China. Energy Policy. 2004;32:1225-9. doi:10.1016/s03014215(03)00086-7.

Yang S, Shen C. A review of electric load classification in smart grid environment. Renew Sustain Energy Rev. 2013;24:103-10. doi:10.1016/j.rser.2013.03.023.

Yuan J, Zhao C, Yu S, et al. Electricity consumption and economic growth in China: cointegration and co-feature analysis. Energy Econ. 2007;29:1179-91. doi:10.1016/j.eneco.2006.09.005.

Zhang M, Song Y, Yao L. Exploring commercial sector building energy consumption in China. Nat Hazards. 2015;75:2673-82. doi:10.1007/s11069-014-1452-5.

Zhang J, Deng S, Shen F, et al. Modeling the relationship between energy consumption and economy development in China. Energy. 2011;36:4227-34. doi:10.1016/j.energy.2011.04.021.

Zheng Y, Luo D. Industrial structure and oil consumption growth path of China: empirical evidence. Energy. 2013;57:336-43. doi:10. 1016/j.energy.2013.05.004.

Zou C, Yang Z, Zhu R, et al. Progress in China's unconventional oil $\&$ gas exploration and development and theoretical technologies. Acta Geol Sin (English Edition). 2015;89:938-71. doi:10.1111/ 1755-6724.12491.

Zhou S, Zhang X. Nuclear energy development in China: a study of opportunities and challenges. Energy. 2010;35:4282-8. doi:10. 1016/j.energy.2009.04.020.

Zhou K, Yang S, Shen C, et al. Energy conservation and emission reduction of China's electric power industry. Renew Sustain Energy Rev. 2015;45:10-9. doi:10.1016/j.rser.2015.01.056. 